\title{
MICRONUTRIENTES NO SISTEMA SOLO-Pinus caribaea Morelet EM PLANTIOS APRESENTANDO AMARELECIMENTO DAS ACÍCULAS E MORTE DE PLANTAS ${ }^{1}$
}

\author{
Roselene de Queiroz Chaves ${ }^{2}$ e Gilberto Fernandes Corrêa ${ }^{3}$
}

\begin{abstract}
RESUMO - Com o objetivo de contribuir no diagnóstico de causas que têm levado à morte precoce de pinheiros, verificada após amarelecimento e necrose progressiva das acículas, foi desenvolvido este estudo em áreas de cerrado, no oeste de Minas Gerais. Foram comparadas árvores de Pinus caribaea Morelet das variedades caribaea e hondurensis, plantadas entre 1977-82. Em cada local de amostragem coletou-se material de 20 árvores, sendo 10 com acículas amarelecidas e 10 normais. Foram coletados acículas e tecidos do xilema e floema de raízes, nos quais foram analisados os teores de $\mathrm{Fe}, \mathrm{Mn}, \mathrm{Zn}, \mathrm{Cu}$ e B. A classe de solo dos sítios de estudo é Latossolo Amarelo ácrico típico. As amostras foram coletadas nas profundidades: 0-5, 5-10, 10-20, 20-40, 40-60, 60-80, 80-100, 100-150, 150-200, 200-250 e 250-300 cm, nas quais foram analisados os teores trocáveis de Fe, Mn, Zn, $\mathrm{Cu}$ e B. Os teores de $\mathrm{Fe}, \mathrm{Zn}, \mathrm{Cu}$ e $\mathrm{B}$ não diferiram significativamente entre acículas verdes e amarelecidas, enquanto os teores de Mn foram significativamente inferiores nestas. Observou-se também que os teores de Mn foram maiores no xilema e menores nas acículas das plantas anormais, ocorrendo o inverso nas plantas normais. Os sintomas visuais, confirmados pelos resultados analíticos, revelam haver deficiência de manganês no sistema solo-planta estudado.
\end{abstract}

Palavras-chave: Pinus tropical, relação solo-planta, deficiência nutricional, área de cerrado e reflorestamento.

\section{MICRONUTRIENTS IN THE SOIL - Pinus caribaea Morelet SYSTEM WITH YELLOWING OF THE NEEDLES FOLLOWED BY SENESCENCE AND DEATH}

\begin{abstract}
This study was carried out to diagnose senescence and death of pine trees (Pinus caribaea Morelet), observed after yellowing and progressive necrosis of the needles in the Brazilian Savanna (Cerrado) in Western Minas Gerais, Brazil. The varieties caribaea and hondurensis, planted between 1977 and 1982 were compared. Samples from twenty trees were collected from the three sites studied; ten with yellowing of the needles and ten without symptoms. From each tree, phloem tissue and xylem from root segments and needles were collected and the contents of $\mathrm{Fe}, \mathrm{Mn}, \mathrm{Zn}, \mathrm{Cu}$ and $\mathrm{B}$ were analyzed. The soil is Yellow Latosol (Typic Acrustox). Soil samples were colleced at the following depths: 0-5, 5-10, 10-20, 20-40, 40-60, 60-80, 80-100, 100-150, 150-200, 200-250 and 250-300 cm. Soil analysis was performed to evaluate the contents of Fe, Mn, Zn, Cu and B concentrations. The mean $\mathrm{Fe}, \mathrm{Zn}, \mathrm{Cu}$ and $\mathrm{B}$ concentrations did not differ significantly in the green and yellowed needles but the Mn contents were significantly lower in the yellowed needles. Visual symptoms and laboratory test revealed a complex Mn deficiency.
\end{abstract}

Key words: $\quad$ Tropical pine, plant soil relation, nutritional deficiency, Brazilian Savanna (Cerrado), and afforestation.

1 Recebido para publicação em 7.8.2002.

Aceito para publicação em 4.11.2003.

Parte da dissertação de mestrado do primeiro autor, parcialmente financiada pela CAPES.

2 Eng.-Agr., M.S., TNS III da Embrapa Arroz e Feijão, Caixa Postal 179, 75375-000 Santo Antônio de Goiás-GO, <roselene@ cnpaf.embrapa.br>. ${ }^{3}$ Prof. Titular do Instituto de Ciências Agrárias (ICIAG) da Universidade Federal de Uberlândia - UFU, Caixa Postal 593, 38400-902 Uberlândia-MG, <gfcorrea@ufu.br>. 


\section{INTRODUÇÃO}

À medida que os empreendimentos florestais vêm sendo implantados em solos de baixa fertilidade natural, cresce a importância de estudos acerca das exigências de micronutrientes pelo Pinus. Pesquisadores como Saur (1990) têm analisado os problemas e o conhecimento atual sobre os micronutrientes em ecossistemas florestais, porém em regiões temperadas.

A diagnose apurada das deficiências nutricionais em um determinado sistema solo-planta é o pré-requisito essencial para a adequada correção do solo.

O gênero Pinus é conhecido pela sua baixa exigência nutricional. São encontradas espécies crescendo em sítios extremamente pobres, nos quais, apesar de a expectativa de produção estar aquém do satisfatório, os pinheiros têm revelado uma capacidade extraordinária de gerenciamento dos parcos recursos nutricionais. O Pinus taeda, por exemplo, é conhecido como sendo uma espécie pioneira nas regiões onde ocorre naturalmente (Reissmann \& Wisniewsky, 2001). Segundo estes autores, o P. elliottii se caracteriza, também, como uma espécie cuja resposta à adubação é observada apenas em sítios extremamente pobres.

Os experimentos de adubação constituem-se na maneira mais eficiente de determinar muitos dos fatores de produção de um certo local e da espécie florestal em estudo (Haag, 1983). Eles fornecem as informações de um sítio e as possibilidades para o desenvolvimento de determinada espécie. Porém, dado ao grande porte e ao longo ciclo de vida das espécies florestais, a necessidade nutricional de algumas ainda é pouco conhecida (Martinez et al., 1985).

Os trabalhos relacionados com a carência nutricional em Pinus no Brasil são bastante raros, sobretudo com Pinus tropicais. Segundo Reissmann \& Wisniewsky (2001), tal fato se deve principalmente à rapidez de crescimento e à ausência de sintomas de deficiência, especialmente durante as primeiras rotações, reforçando a expectativa de que o Pinus, de modo geral, dispensa grandes cuidados com adubação, ou ainda que esta é totalmente dispensável.

Apesar da grande plasticidade genética da espécie Pinus caribaea Morelet, isto é, sua capacidade de adaptação mesmo em ambientes diferentes daqueles dos centros de origem, certos limites não podem ser ultrapassados (Lima, 1990). Torna-se, portanto, necessário que

R. Árvore, Viçosa-MG, v.27, n.6, p.769-778, 2003 os dados de pesquisas subsidiem os empreendimentos florestais com esta espécie, aliando conhecimentos do comportamento da planta com estudos do sítio de plantio.

O problema da morte precoce de pinheiros tropicais tem chamado a atenção de setores empresariais e da pesquisa, na região oeste de Minas Gerais. A intensidade do problema varia com as condições edáficas, havendo uma certa relação entre as condições de drenagem do solo e a ocorrência dos sintomas de senescência de plantas.

O sintoma nos pinheiros consiste no amarelecimento das acículas, que ocorre da ponta para a base destas, evoluindo para um tom pardo-avermelhado. Associado a este quadro, verificam-se exsudados de resina no vértice das acículas. Estes sintomas são mais intensos na parte superior da copa. $\mathrm{O}$ amarelecimento se intensifica na planta, levando à queda das acículas, morte e posterior queda do pinheiro. Contudo, a ocorrência destas sintomatologias não se dá em reboleiras, mas sim distribuída de forma aparentemente aleatória nos talhões, tanto em árvores dominadas como em dominantes.

Esse quadro indica tratar-se essencialmente de problemas nutricionais e propicia um estudo sobre oligoelementos em Pinus tropicais, gerando informações que têm sido requeridas para sua melhor produtividade em Latossolos fase cerrado.

Tendo em vista a importância da silvicultura nas regiões do Triângulo Mineiro e Alto Paranaíba, sobretudo com espécies de Pinus tropicais, devido ao diversificado parque industrial já implantado, é necessário um suporte da pesquisa a fim de garantir a continuidade desta atividade de forma sustentável. Com essa premissa, desenvolveu-se este estudo, orientado para o diagnóstico de deficiências nutricionais e sua relação com a morte precoce de pinheiros (Pinus caribaea Morelet), verificada após o amarelecimento e a necrose progressiva das acículas.

\section{MATERIAL E MÉTODOS}

Com o objetivo de obter a máxima representatividade das condições de solo e dos sistemas silviculturais da maior parte dos reflorestamentos em áreas de cerrado do oeste de Minas Gerais, foram selecionados três sítios de amostragem em que o solo, de acordo com EMBRAPA (1999), pertence à classe Latossolo Amarelo ácrico típico (LA). 
Foram escolhidos talhões de Pinus caribaea Morelet var. caribaea e var. hondurensis Barr. et Golf. em idade comercial de corte, a fim de estudar áreas sob manejo florestal pelo maior tempo possível, apresentando pinheiros com sintomas bem característicos de senescência precoce (Figura 1). Algumas características dos locais de estudo estão resumidas no Quadro 1.
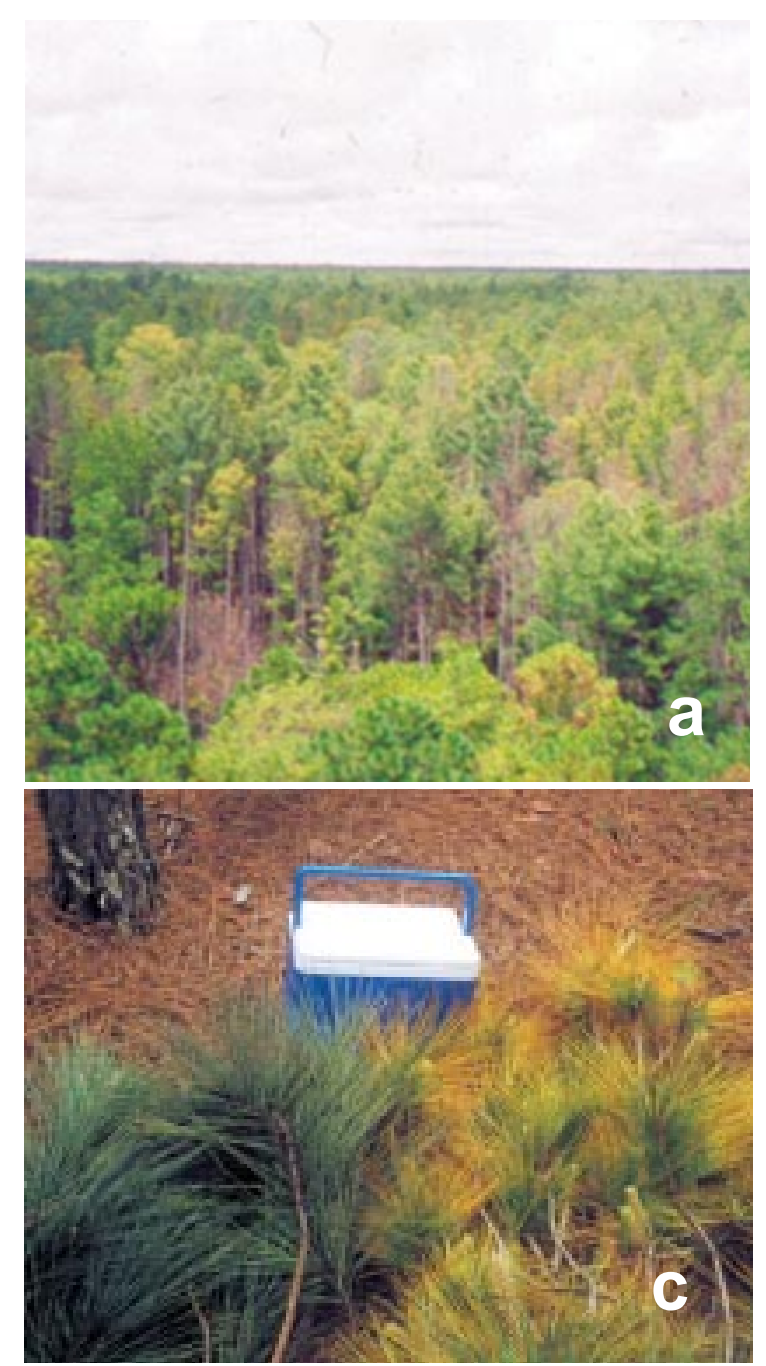

A amostragem do solo foi realizada a partir do preparo de uma seção de cortes (com auxílio de enxadão e faca), que permitiu retirar as primeiras amostras (0-5, 5-10 e 10-20 cm). Em seguida, nas demais profundidades $(20-40,40-60,60-80,80-100,100-150,150-200$, 200-250 e 250-300 cm), as amostragens foram feitas por tradagem.

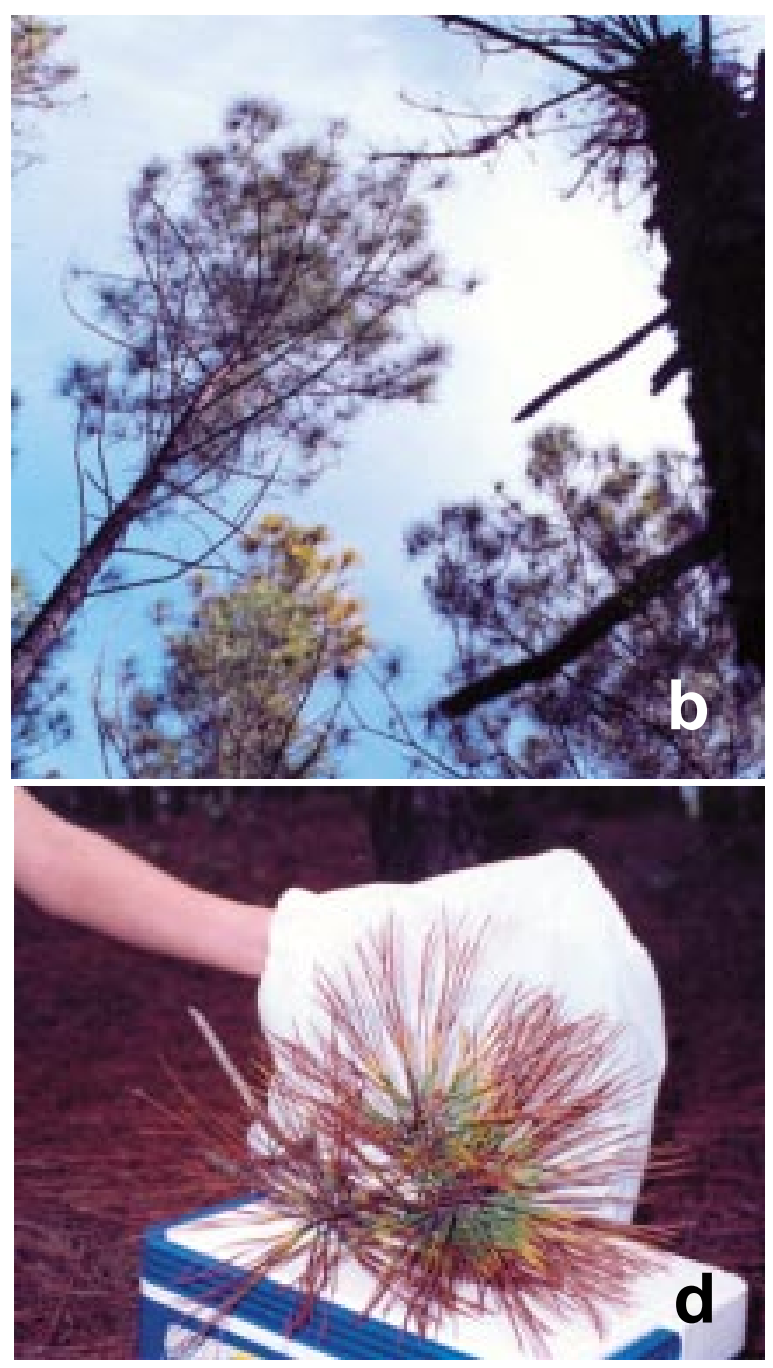

Figura 1 - Talhão de Pinus caribaea var. hondurensis apresentando plantas amarelecidas e outras já em franco processo de definhamento e morte (a); planta de Pinus caribaea var. caribaea morta, ladeada por outras apresentando diferentes estádios/intensidades de amarel ecimento/queda das acículas (b); gal hos col etados em plantas dePinus caribaea var. caribaea normais (verde-intenso) e anormais (amarelo) (c); e aspecto das acículas de Pinus caribaea var. caribaea apresentando amarelecimento que progride da ponta para a base destas, evoluindo para uma coloração pardo-avermelhada (d).

Figure 1 - Pinus caribaea var. hondurensis patch showing yel lowed plants with somein a steady process of senescenceand death (a); Dead Pinus caribaea var. caribaea plant, surrounded by plants showing different stages of the yellowing process and needle loss (b); Branches taken from healthy (intense green) and sick (yellow) Pinus caribaea var. caribaea plants (c); Aspect of the Pinus caribaea var. caribaea needles showing the yellowing increase from the tip to the basis of the needle, reaching a reddish-brown color (d). 
Quadro 1 - Resumo das principais características descritivas dos Locais I, II e III Table 1 - Summary of the main features of sites I, II and III

\begin{tabular}{|c|c|c|c|}
\hline Variável & Local I & Local II & Local III \\
\hline Município & Uberlândia & Uberlândia & Romaria \\
\hline Empresa & Pinusplan & Pinusplan & Satipel \\
\hline Local & Floresta do Lobo & Floresta do Lobo & Nova Monte Carmelo S.A. \\
\hline $\mathrm{N}^{0}$ do talhão & 18 & 302 & 1267 \\
\hline Variedade & caribaea & caribaea & hondurensis \\
\hline Ano do plantio & 1982 & 1978 & 1977 \\
\hline Espaçamento (m) & $2,50 \times 2,80$ & $2,00 \times 2,80$ & $2,00 \times 3,00$ \\
\hline $\mathrm{N}^{0}$ plantas/ha & 1428 & 1785 & 1667 \\
\hline Adubação de plantio & $10 \mathrm{~g}$ superfosfato simples/ cova & $10 \mathrm{~g}$ superfosfato simples/ cova & sem adubação \\
\hline
\end{tabular}

As análises químicas de solo para os micronutrientes $\mathrm{Fe}, \mathrm{Mn}, \mathrm{Zn}, \mathrm{Cu}$ e B foram realizadas segundo metodologia descrita por Silva (1999). Foram utilizadas as instalações do Laboratório de Análises de Solos (LABAS) do Instituto de Ciências Agrárias da Universidade Federal de Uberlândia (UFU).

A análise do material vegetal incluiu parte aérea (acículas) e raízes (floema e xilema). Foram amostradas, em cada local, acículas da porção mediana da copa, nos quatro pontos cardeais, em dez plantas normais (coloração verde-intensa) e em dez plantas anormais (coloração amarela). Os tecidos do floema e do xilema foram coletados em raízes de quatro árvores normais e quatro anormais, em cada local. Estes materiais foram secos em estufa de ventilação forçada a $65^{\circ} \mathrm{C}$, até peso constante, e, então, finamente moídos e submetidos às análises para determinação dos nutrientes $\mathrm{Fe}, \mathrm{Mn}, \mathrm{Zn}, \mathrm{Cu}$ e B, conforme descrito por Silva (1999). Estas análises foram realizadas no Laboratório de Solos Florestais da Universidade Federal de Viçosa (UFV).

O tratamento estatístico empregado foi a estimação de parâmetros por intervalo, considerando que os pinheiros não foram amostrados ao acaso, uma vez que para o estudo proposto era necessário selecionar árvores com e sem sintomas de senescência precoce. Como as amostras eram pequenas, utilizou-se a distribuição $t$ de Student. Sendo assim, a expressão utilizada para calcular o intervalo de confiança da média foi

$$
\left(\bar{x} \pm t_{n-1 ; \alpha / 2} s_{x} / \sqrt{n}\right)
$$

em que $t$ é o valor crítico da distribuição de Student à significância $\alpha=0,05$. Como o teste é bilateral, na

R. Árvore, Viçosa-MG, v.27, n.6, p.769-778, 2003 expressão aparece: $\alpha / 2$. O fator $n$ refere-se ao número de árvores, sendo ressaltado que cada árvore corresponde a uma repetição. A interpretação a ser feita é a de que existe uma probabilidade de $95 \%$ de o intervalo encontrado $(\chi)$ conter a verdadeira média da população. A hipótese $\mathrm{H}_{0}$ adotada foi a de que a concentração dos nutrientes no tecido vegetal é igual nos dois tipos de planta (normais e anormais). Sendo assim, aceitou-se $\mathrm{H}_{0}$ quando os intervalos de confiança foram coincidentes entre plantas normais e anormais.

\section{RESULTADOS E DISCUSSÃO}

Os teores de $\mathrm{Fe}, \mathrm{Mn}, \mathrm{Zn}, \mathrm{Cu}$ e B, nos três sítios amostrados, encontram-se no Quadro 2. Estes micronutrientes estão, em geral, em níveis baixos para $\mathrm{Zn}$ e Mn, muito baixos para $\mathrm{B}$ e altos para $\mathrm{Cu}$ e $\mathrm{Fe}$, de acordo com a CFSEMG (1999). Porém, o reflorestamento com Pinus caribaea parece não influenciar significativamente os teores de micronutrientes no solo. Por exemplo, Lilienfein et al. (2000) não encontraram diferença significativa nos teores de $\mathrm{Cu}, \mathrm{Fe}, \mathrm{Mn}$ e $\mathrm{Zn}$ entre solos sob vegetação original de cerrado e sob Pinus caribaea.

Os teores encontrados no material vegetal concordam com os dados de Drumond (1985) para Pinus caribaea var. hondurensis aos 10 anos de idade, em um Latossolo Vermelho-Amarelo A (1834 árvores/ha). O autor concluiu que a extração de micronutrientes em $\mathrm{g} / \mathrm{ha}$ foi de 14.274 para o Mn, 7.289 para o $\mathrm{Fe}, 1.938$ para o Cu e de 1.002 para o Zn. Estes números confirmam as constatações de que na liteira do Pinus ocorre acúmulo de $\mathrm{Mn}, \mathrm{Fe}$ e $\mathrm{Cu}$ e que a sequiência de extração de micronutrientes do solo seria Mn $>\mathrm{Fe}>\mathrm{Zn}>\mathrm{B}>\mathrm{Cu}$ (LA TORRACA et al., 1984). 
Os teores de micronutrientes (B, $\mathrm{Cu}, \mathrm{Fe}, \mathrm{Mn}$ e $\mathrm{Zn}$ ) determinados no material vegetal em estudo encontramse no Quadro 3. Observa-se, quanto à ordem relativa das concentrações de micronutrientes, a seqüência $\mathrm{Fe} \approx \mathrm{Mn}$ $>\mathrm{Zn}>\mathrm{B}>\mathrm{Cu}$ no componente acícula. No floema da casca da raiz foi encontrada a seguinte ordem: $\mathrm{Fe}>\mathrm{Mn}$ $>\mathrm{Zn}=\mathrm{B}>\mathrm{Cu}$, enquanto no lenho externo (xilema) da raiz observou-se a sequiência: $\mathrm{Fe}>\mathrm{Mn}>\mathrm{B}>\mathrm{Zn}=\mathrm{Cu}$. Estas seqüências são similares àquelas encontradas por Castro et al. (1980).

\subsection{Boro (B)}

No Quadro 3, constata-se que as duas variedades de Pinus caribaea estudadas são igualmente exigentes neste micronutriente. Os valores muito baixos de B, presentes no solo (Quadro 2), demonstram ser esta espécie eficiente na absorção e utilização deste elemento. Quanto ao nível crítico de boro para Pinus, Stone \& Will (1965), citados por Haag et al. (1991b), relataram teores em torno de 8 ppm e sugeriram que concentrações acima de 3 a 4 ppm podem ser suficientes para um desenvolvimento normal, se a absorção é ininterrupta ou se a taxa de crescimento é retardada por outros fatores. Além disso, segundo Haag et al. (1991b), o transporte de B é dependente da transpiração. Desta forma, as relações hídricas no sistema solo-planta-atmosfera afetam sua distribuição e, portanto, podem variar de um local para outro. Mais importante do que o valor absoluto da concentração é a garantia de um suprimento contínuo deste nutriente.

\subsection{Cobre $(\mathrm{Cu})$}

O cobre é o micronutriente exigido em menor quantidade pelo Pinus. Will (1972), citado por Haag et al. (1991b), salienta que o valor crítico de $\mathrm{Cu}$ pode variar com os níveis de outros nutrientes, particularmente nitrogênio e fósforo. É importante notar que a participação do $\mathrm{Cu}$ (concentração) na planta foi: lenho externo (xilema) > acículas > casca, o que concorda com Haag et al. (1991b), que encontraram para as variedades hondurensis, caribaea e bahamensis teores também mais baixos que os referenciados na literatura como sendo níveis críticos de $\mathrm{Cu}$ em Pinus.

Segundo Lastra et al. (1988), o maior teor de $\mathrm{Cu}$ nas raízes é um mecanismo protetor da espécie contra o aumento deste elemento nas acículas, onde poderia apresentar efeito deletério ao sistema fotossintético. Todavia, a variedade hondurensis apresentou teor de $\mathrm{Cu}$ nas acículas quase quatro vezes maior que para a variedade caribaea, revelando ser aquela variedade mais eficiente na absorção (Quadro 3), o que concorda com os dados de Haag et al. (1991b), que trabalharam em solução nutritiva.

A variabilidade entre os teores de $\mathrm{Cu}$ no lenho e na casca das raízes, como pode ser visto no Quadro 3, com valores variando de traços deste elemento até $15 \mathrm{ppm}$, pode ser explicada com as considerações de Lastra et al. (1988), de que ocorrem acúmulos pontuais de $\mathrm{Cu}$, aprisionado nas paredes das células radiculares, na forma

Quadro 2 - Teores de Fe, Mn, Zn, Cu e B no solo dos locais I, II e III

Table $2-F e, M n, Z n, C u$ and $B$ contents, in the soil of the three sites sampled

\begin{tabular}{|c|c|c|c|c|c|c|c|c|c|c|c|c|c|c|c|}
\hline \multirow{3}{*}{$\begin{array}{l}\text { Profundidade } \\
\quad(\mathrm{cm})\end{array}$} & \multicolumn{3}{|c|}{ Ferro } & \multicolumn{3}{|c|}{ Manganês } & \multicolumn{3}{|c|}{ Zinco } & \multicolumn{3}{|c|}{ Cobre } & \multicolumn{3}{|c|}{ Boro } \\
\hline & \multicolumn{15}{|c|}{$\mathrm{mg} / \mathrm{dm}^{3}(\mathrm{ppm})$} \\
\hline & I & II & IIII & I & II & IIII & I & II & IIII & I & II & IIII & I & II & IIII \\
\hline $0-5$ & 75 & 50 & 60 & 1,0 & 0,4 & 0,3 & 0,3 & 0,3 & 0,5 & 0,9 & 0,9 & 1,3 & 0,13 & 0,14 & 0,14 \\
\hline $5-10$ & 50 & 43 & 50 & 1,1 & 0,4 & 0,3 & 0,3 & 0,1 & 0,3 & 1,0 & 1,0 & 1,0 & 0,16 & 0,09 & 0,11 \\
\hline $10-20$ & 40 & 33 & 40 & 0,7 & 0,2 & 0,3 & 0,1 & 0,1 & 0,4 & 1,1 & 0,6 & 1,0 & 0,14 & 0,11 & 0,11 \\
\hline $20-40$ & 35 & 24 & 30 & 0,8 & 0,3 & 0,3 & 0,5 & 0,1 & 0,3 & 1,1 & 0,7 & 0,6 & 0,16 & 0,04 & 0,11 \\
\hline $40-60$ & 21 & 17 & 15 & 1,0 & 0,4 & 0,3 & 0,7 & 0,2 & 0,5 & 0,9 & 0,9 & 0,8 & 0,13 & 0,06 & 0,06 \\
\hline $60-80$ & 23 & 10 & 10 & 1,3 & 0,4 & 0,3 & 0,2 & 0,3 & 0,3 & 0,7 & 0,7 & 0,3 & 0,07 & 0,03 & 0,06 \\
\hline $80-100$ & 25 & 10 & 08 & 1,0 & 0,5 & 0,4 & 0,5 & 0,5 & 0,6 & 0,5 & 0,6 & 0,5 & 0,04 & 0,02 & 0,08 \\
\hline $100-150$ & 13 & 07 & 08 & 1,2 & 0,5 & 0,4 & 0,2 & 0,8 & 0,3 & 0,4 & 0,2 & 0,1 & 0,04 & 0,04 & 0,02 \\
\hline $150-200$ & 07 & 12 & 06 & 0,6 & 0,4 & 0,5 & 0,5 & 1,3 & 0,5 & 0,2 & 0,2 & 0,4 & 0,02 & 0,02 & 0,00 \\
\hline $200-250$ & 06 & 11 & 05 & 0,3 & 0,6 & 0,7 & 0,2 & 0,7 & 0,4 & 0,2 & 0,1 & 0,3 & 0,01 & 0,01 & 0,03 \\
\hline $250-300$ & 13 & 07 & 04 & 0,6 & 0,7 & 0,5 & 0,9 & 1,4 & 0,3 & 0,4 & 0,2 & 0,3 & 0,00 & 0,02 & 0,00 \\
\hline
\end{tabular}


Quadro 3 - Teores médios de $\mathrm{Zn}, \mathrm{B}, \mathrm{Cu}, \mathrm{Fe}$ e $\mathrm{Mn}$ no material vegetal de plantas normais e anormais de Pinus caribaea Morelet nos Locais I, II e III

Table 3 - Average $\mathrm{Zn}, \mathrm{B}, \mathrm{Cu}, \mathrm{Fe}$ and $\mathrm{Mn}$ contents in the vegetal material of healthy and diseased of Pinus caribaea Morelet in the three (I, II and III) sites sampled

\begin{tabular}{|c|c|c|c|c|c|c|c|c|c|c|c|c|c|c|c|c|}
\hline \multirow{3}{*}{$\begin{array}{c}\text { Material } \\
\text { Vegetal }\end{array}$} & \multirow{3}{*}{ Pinheiro } & \multicolumn{3}{|c|}{ Zinco } & \multicolumn{3}{|c|}{ Boro } & \multicolumn{3}{|c|}{ Cobre } & \multicolumn{3}{|c|}{ Ferro } & \multicolumn{3}{|c|}{ Manganês* } \\
\hline & & \multicolumn{15}{|c|}{$\mathrm{mg} / \mathrm{kg}(\mathrm{ppm})$} \\
\hline & & I & II & IIII & I & II & IIII & I & II & IIII & I & II & IIII & I & II & IIII \\
\hline \multirow{2}{*}{ Acículas } & Normais & 9,4 & 13,0 & 11,9 & 10,8 & 9,7 & 9,2 & 0,4 & 0,5 & 2,3 & 117,9 & 159,2 & 105,9 & 256,9 & 206,5 & 148,5 \\
\hline & Anormais & 12,2 & 8,4 & 13,1 & 9,6 & 9,1 & 11,6 & 0,9 & 0,8 & 2,6 & 102,0 & 105,5 & 102,8 & 77,2 & 57,8 & 58,3 \\
\hline \multirow{2}{*}{$\begin{array}{l}\text { Casca } \\
\text { (floema) }\end{array}$} & Normais & 7,2 & 12,3 & 14,4 & 11,8 & 15,2 & 13,3 & 2,1 & 0,2 & 0,3 & $1.028,6$ & 797,3 & 195,0 & 43,5 & 37,2 & 94,4 \\
\hline & Anormais & 7,7 & 14,4 & 14,7 & 10,9 & 15,1 & 12,2 & 2,0 & 0,1 & 0,8 & 797,3 & 384,8 & 134,0 & 92,2 & 112,8 & 101,6 \\
\hline \multirow{2}{*}{$\begin{array}{l}\begin{array}{l}\text { Lenho Externo } \\
\text { (xilema) }\end{array} \\
\end{array}$} & Normais & 3,6 & 3,0 & 3,4 & 7,8 & 6,6 & 7,2 & 3,5 & 0,0 & 15,1 & 387,0 & 50,4 & 40,8 & 34,6 & 16,2 & 30,5 \\
\hline & Anormais & 4,2 & 3,5 & 3,8 & 8,0 & 7,4 & 8,0 & 0,0 & 4,7 & 1,7 & 112,8 & 59,8 & 30,9 & 64,9 & 32,5 & 41,4 \\
\hline
\end{tabular}

* Houve diferença significativa somente quanto ao teor de Mn em todas as partes da planta, entre pinheiros normais e anormais, a 5\% pelo teste t de Student.

de complexos funcionais com átomos de $\mathrm{N}, \mathrm{O}$ ou $\mathrm{S}$ e em peptídios de metais pesados, as fitoquelatinas. É possível, portanto, que a amostragem destes tecidos não tenha sido adequada para dosar o teor de cobre.

\subsection{Ferro (Fe)}

Em condições de campo, não foi encontrada referência à deficiência de Fe em plantas do gênero Pinus, pois estas geralmente são estabelecidas em terrenos ácidos, onde o teor deste micronutriente não é limitante. Em uma revisão acerca do Fe em Pinus, Martinez et al. $(1985,1986)$ encontraram valores entre 10 e 393 ppm de Fe nas acículas, sem registro de problemas de deficiência ou toxidez deste nutriente. Os teores de $\mathrm{Fe}$ em acículas obtidos no presente trabalho correspondem aos encontrados por esses autores para as variedades caribaea e honduresnsis. Eles relataram, também, o fato de as raízes apresentarem maior concentração de ferro, sobretudo na casca, com cerca de cinco vezes mais $\mathrm{Fe}$ que nas acículas, a exemplo dos dados apresentados no Quadro 3. Lastra et al. (1988) também observaram este fato, atribuindo-o a uma rápida absorção de $\mathrm{Cu}^{+2} \mathrm{e} \mathrm{Fe} \mathrm{Fe}^{+2}$ com lenta mobilização para a parte aérea, o que segundo os autores está de acordo com os relevantes papéis desses micronutrientes nas cadeias respiratórias mitocondriais, muito ativas nas raízes.

É interessante notar que a variedade hondurensis (Local III) apresenta teores de Fe inferiores àqueles encontrados na variedade caribaea, sobretudo na casca (floema) das raízes, o que concorda com Martinez et al. (1992), que concluíram ser aquela variedade pouco

R. Árvore, Viçosa-MG, v.27, n.6, p.769-778, 2003 exigente em Fe. Estes autores estudaram as três variedades de $P$. caribaea, em solução nutritiva com Fe e na ausência deste. Sob suficiência de Fe, os teores nos diversos tecidos foram semelhantes entre as variedades, porém sob omissão a variedade hondurensis mostrou teores inferiores aos das demais, nas acículas e nas raízes. Também o teor de Fe em diferentes partes da planta, na var. hondurensis, que era semelhante ao das demais sob suficiência, sofreu a maior queda porcentual sob suprimento limitado. Tal fato evidencia que o solo do Local III apresenta um teor de Fe possivelmente aquém do ótimo para a var. hondurensis, pois, conforme o Quadro 3, o teor de Fe, sobretudo na casca (floema) das raízes, é consideravelmente menor em relação à variedade caribaea.

\subsection{Manganês (Mn)}

Dentre os cinco micronutrientes avaliados no material vegetal, o único que pode ser relacionado aos sintomas de amarelecimento é o Mn, pois apresenta diferença significativa no seu teor, entre plantas normais e anormais, nos três locais e nas diferentes partes avaliadas na planta (Quadro 3).

Neste estudo os maiores teores de Mn no solo ocorrem no Local I (Quadro 2). Este corresponde ao talhão mais recente e com menor densidade de plantas (Quadro 1). Cabe ressaltar que as diferenças no histórico de manejo, no que se refere aos desbastes, não estão sendo consideradas.

Apesar de o Mn ser um nutriente muito similar ao Fe, tanto em comportamento químico como em ocorrência 
geológica, ele apresenta maior mobilidade (Saur, 1990), o que se deve à sua natureza mais eletropositiva e à maior solubilidade de seus compostos. Este fato deve contribuir para que ocorra maior lixiviação do $\mathrm{Mn}$ em relação ao Fe.

Segundo Camargo (1991), intensa lixiviação do Mn pode ocorrer, ao longo do tempo, se o pH é baixo. O autor cita ainda o trabalho de Godo \& Reisenauer (1980), que encontraram que a solubilidade do $\mathrm{Mn}^{+2}$ aumentou com a diminuição do $\mathrm{pH}$ e a absorção pela raiz diminuiu, indicando que os exsudados orgânicos desta formam complexos com o $\mathrm{Mn}^{+2}$. Estes autores encontraram $93 \%$ do Mn em solução em forma complexada com a matéria orgânica.

A análise dos resultados para Mn tem como complicador o fato de as variações em seus níveis na planta serem acentuadas, fato visível no Quadro 3. Cameron et al. (1982), citados por Martinez et al. (1992), consideraram como níveis normais teores entre 82 e 109 ppm, na matéria seca de acículas de plantas adultas de P. caribaea var. hondurensis. Os autores citam também Knight (1978), que encontrou grande variação nos níveis de Mn em acículas maduras de $P$. radiata com 4 anos de idade, tendo constatado variação estacional entre talhões e no mesmo talhão.

Verifica-se que as plantas anormais estão com deficiência de Mn nas acículas, apesar de contê-lo em quantidade considerável na raiz, enquanto as plantas normais apresentam teores considerados como normais nas acículas (Haag et al., 1991a) e uma quantidade bem menor na raiz (Quadro 3). Este fato ocorre, igualmente, para as duas variedades em estudo. $\mathrm{O}$ padrão normal de extração de Mn, para as variedades de $P$. caribaea estudadas por Martinez et al. (1992), em solução nutritiva, foi teor nas acículas $=$ nos ramos $=$ nas raízes. Quando o suprimento de Mn foi limitado, as acículas passaram a exibir teores de Mn mais altos que nos ramos e nas raízes. Tudo leva a crer que, como o suprimento de Mn está limitado pelos níveis muito baixos encontrados no solo, sua alocação preferencial está se dando nas acículas, o que está de acordo com Mengel \& Kirkby (1982). Segundo estes autores, apesar da baixa mobilidade, o Mn é translocado preferencialmente para as regiões de crescimento, sendo os órgãos mais jovens mais ricos nesse nutriente. Esse comportamento também condiz com o papel do Mn na reação de Hill, responsável pela fotólise da água e evolução do $\mathrm{O}_{2}$ no fotossistema II da fotossíntese (Marschner, 1986, citado por Martinez et al., 1992).

Como o padrão de comportamento para o Mn nas plantas deste gênero é extremamente variável, as plantas anormais seriam aquelas que não são capazes de alterar seu comportamento de extração e alocação deste nutriente, mesmo em condições de suprimento limitado. Tal fato pode ser explicado por Graham (1988), que relatou que algumas plantas têm certa tolerância genética à deficiência de Mn. De acordo com o autor, estas plantas apresentam um mecanismo de ajuste ao estresse nutricional, de modo a garantir um suprimento mínimo quando a concentração de Mn na solução do solo diminui. Fazem parte destes mecanismos de ajuste o aumento da proporção relativa do sistema radicular, ou seja, o aumento da relação raiz : parte aérea, a redução do $\mathrm{K}_{\mathrm{m}}$ (que mede a afinidade entre o íon e o seu carregador) e o aumento do número de moléculas do carregador em nível radicular.

Graham (1988) citou o trabalho de Memon et al. (1987), que analisaram os teores de $\mathrm{Cu}, \mathrm{Fe}$ e Mn em 60 espécies da floresta temperada do Japão, encontrando uma enorme variabilidade na concentração do $\mathrm{Mn}$, em comparação ao $\mathrm{Cu}$ e Fe. Todas as espécies foram coletadas numa mesma ocasião, desenvolvendo-se sobre o mesmo tipo de solo. Os teores, em $\mathrm{mg} / \mathrm{kg}$, variaram entre 2,3 - 11,1 para o $\mathrm{Cu}, 52$ - 229 para o Fe e 26-4.632 para o Mn. Dechen et al. (1991a) relataram que o Mn parece ser facilmente absorvido pelas plantas, quando ocorre na forma solúvel no solo, existindo uma relação direta entre o teor solúvel do elemento no solo e a concentração na planta.

Existem outras propostas que não podem ser descartadas, como a deficiência de Mn induzida pelo Fe, já que ocorre uma inibição competitiva no processo de absorção iônica destes nutrientes. Segundo Malavolta (1980), o Fe e o Mn combinam com o mesmo sítio do carregador, sendo o Fe mais inibidor, ou seja, mais reativo, por apresentar menor raio iônico. Este mecanismo de absorção do Fe e do Mn é um agravante em sistemas iguais ao enfocado neste estudo, onde não se verifica carência de Fe, mas o Mn encontra-se em baixos teores.

Outra hipótese, aplicável ao gênero Pinus, é a de que ocorre uma exsudação radicular de compostos orgânicos, como aminoácidos, açúcares e ácidos orgânicos, os quais alteram a flora microbiana que se alimenta desses exsudatos e têm um papel importante no estado de oxidação do Mn do solo. Segundo Lucas \& Knezek (1972),

R. Árvore, Viçosa-MG, v.27, n.6, p.769-778, 2003 
em certas condições, estes compostos promovem a oxidação do $\mathrm{Mn}^{+2}$ a Mn ${ }^{+4}$ próximo às raízes, acentuando a deficiência deste nutriente. Sendo assim, algum genótipo dentro da mesma variedade poderia exsudar compostos com maior poder oxidante de Mn que outro.

Os resultados analíticos, juntamente com os sintomas visuais de deficiência, revelam ser o Mn um dos responsáveis pelo problema em estudo. $\mathrm{O}$ fato de este amarelecimento ocorrer mais tardiamente na floresta, bem como a sintomatologia de deficiência apresentada pelas plantas, concordam plenamente com o estudo de Martinez et al. (1992), que acompanharam $P$. caribaea (variedades hondurensis, bahamensis e caribaea) em solução nutritiva. Nesse estudo, os sintomas de deficiência de Mn e de $\mathrm{Zn}$ foram os que demoraram mais tempo para se manifestar. Os sintomas por eles descritos para a deficiência de Mn coincidem com os visualizados nos talhões objetos deste estudo, que por sua vez concordam com os descritos por Malavolta (1974), para Pinus. Estes se manifestam com uma coloração verde-clara na posição apical das plantas, acompanhada de murcha e necrose da ponta das acículas (a mancha clorótica caminha do ápice para a base das acículas e depois se torna marron). Os sintomas são semelhantes aos de deficiência de ferro, progredindo do ápice para a base da planta, além de surgirem brotações laterais tortuosas.

Também há ocorrência de acículas espetadas, pequenas e duras, havendo grande brotação fascicular na região mediana e apical das plantas. Um sintoma característico é a presença de gota de resina no vértice do ângulo da acícula. Depois de alguns meses o pinheiro apresenta suas acículas totalmente amarelo-avermelhadas. Há queda generalizada destas acículas e, em seguida, o pinheiro, praticamente reduzido ao fuste, também tomba ao chão.

Todo esse acelerado processo de senescência e morte encontra explicações em estudos como os de Borkert (1989), que descreve como sendo os cloroplastos os mais sensíveis de todos os componentes da célula à deficiência de $\mathrm{Mn}$, e a conseqüência disso é o aparecimento de uma desordem na sua estrutura, com reflexos negativos na atividade fotossintética. Dechen et al. (1991b) relataram que o Mg pode substituir o Mn em várias de suas funções bioquímicas, entre elas nas pontes entre o ATP e as enzimas transferidoras de grupos fosfoquinases e fosfotransferases e no ciclo dos ácidos tricarboxílicos. Porém, diante de um quadro de deficiência também de $\mathrm{Mg}$, tudo indica não estar ocorrendo este efeito paliativo.

R. Árvore, Viçosa-MG, v.27, n.6, p.769-778, 2003

\subsection{Zinco (Zn)}

A participação quantitativa do zinco na planta, de acordo com o Quadro 3, foi acículas = casca $>$ madeira. Martinez et al. (1992) advertiram para o fato de o Zn, nas acículas, não ser um bom indicador do estado nutricional quanto a esse mineral. Entretanto, como não houve diferenças significativas entre plantas normais e anormais, quanto ao teor de $\mathrm{Zn}$, em nenhuma parte estudada da planta (Quadro 3), este nutriente não parece estar relacionado aos sintomas em estudo. Os teores de Zn encontrados estão dentro dos limites propostos por Haag et al. (1991b). A espécie $P$. caribaea parece ser muito pouco exigente em $\mathrm{Zn}$, diante dos baixos teores encontrados no solo estudado.

Como já citado, os sintomas de deficiência de Zn foram os últimos a aparecer nos estudos de Martinez et al. (1992), com Pinus caribaea em solução nutritiva. Mengel \& Kirby (1982) citam o fato de a má nutrição fisiológica com Zn em Pinus ser um fenômeno sobre o qual não se tem perfeita compreensão, mas parece estar relacionada à interferência de elementos como $\mathrm{P}, \mathrm{Fe}$ e $\mathrm{Mn}$. Como estes nutrientes, principalmente o $\mathrm{P}$ e o $\mathrm{Mn}$, encontramse em baixas concentrações no solo estudado, não devem estar ocorrendo efeitos antagônicos.

O teor de $\mathrm{Zn}$ na casca, semelhante ao encontrado nas acículas, deve estar relacionado com o que foi postulado por McGrath \& Robson (1984), citados por Martinez et al. (1992). Segundo estes, o processo de concentração de $\mathrm{Zn}$ nos ramos de Pinus parece ser um processo físico-químico, não-metabólico, que ocorre em situações de provisão escassa de Zn pelo solo. Este processo estaria relacionado à troca catiônica nas paredes do xilema e à formação de complexos, por exemplo o Zn-citrato. Os autores discutiram, ainda, que a retenção do $\mathrm{Zn}$ nos ramos de plântulas deficientes neste nutriente pode ter valor adaptativo, visto que a sobrevivência de plantas lenhosas perenes requer a preservação dos ramos e que a sobrevivência destes durante períodos de estresse nutricional é essencial, pelo menos até que as estruturas reprodutivas estejam formadas. Sendo assim, a capacidade de estocar nutrientes nos tecidos das raízes, o que parece ocorrer para os cinco micronutrientes estudados (Quadro 3), pode ser um tampão contra a estacionalidade do crescimento.

\section{CONCLUSÃO}

A pobreza de nutrientes no solo e a não-correção desta deficiência desde a implantação dos pinheirais 
levaram as populações de Pinus estudadas a um processo de declínio por exaustão nutricional.

Os resultados analíticos concernentes ao teor de micronutrientes no solo e no material vegetal, juntamente com os sintomas visuais de amarelecimento das acículas e morte precoce de pinheiros, revelam haver deficiência de manganês no sistema solo-planta estudado.

\section{AGRADECIMENTO}

À Satipel Florestal e sua equipe técnica e à Pinusplan Reflorestadora Ltda., pelo apoio e pela infra-estrutura disponíveis durante a realização deste trabalho; à UFV, na pessoa do professor Dr. Nairam Félix de Barros, pela disponibilização dos laboratórios; e à CAPES, pela bolsa concedida.

\section{REFERÊNCIAS BIBLIOGRÁFICAS}

BORKERT, C. M. Micronutrientes na planta. In: BÜLL, L. T.; ROSOLEM, C. A. (Eds.) In: Interpretação de análise química de solo e plantas para fins de adubação. Botucatu: Fundação de Estudos e Pesquisas Agrícolas e Florestais, 1989. p. 309-329.

CAMARGO, O. A. Reações e interações de micronutrientes no solo. In: FERREIRA, M. E.; CRUZ, M. C. P. (Eds.) Micronutrientes na agricultura. Piracicaba: POTAFOS/ CNPq, 1991. p. 243-272.

CASTRO, C. F. A.; POGGIANI, F.; NICOLIELO, N. Distribuição da fitomassa e nutrientes em talhões de Pinus oocarpa com diferentes idades. IPEF, n. 20, p. 61-74, 1980.

COMISSÃO DE FERTILIDADE DO SOLO DO ESTADO DE MINAS GERAIS - CFSEMG. Recomendações para o uso de corretivos e fertilizantes em Minas Gerais. $5^{\text {a }}$ aproximação. Viçosa-MG: UFV, 1999. 359 p.

DECHEN, A. R.; HAAG, H. P.; CARMELLO, Q. A. C. Funções dos micronutrientes nas plantas. In: FERREIRA, M. E.; CRUZ, M. C. P. (Eds.) Micronutrientes na agricultura. Piracicaba: POTAFOS/CNPq. 1991a. p. 6578.

DECHEN, A. R.; HAAG, H. P.; CARMELLO, Q. A. C. Mecanismos de absorção e de translocação de micronutrientes. In: FERREIRA, M. E.; CRUZ, M. C. P. (Eds.) Micronutrientes na agricultura. Piracicaba: POTAFOS/CNPq. 1991b. p. 79-97.
DRUMOND, M. A. Distribuição de biomassa arbórea e dos nutrientes em plantações puras e consorciadas de Liquidambar styracifua L. e Pinus caribaea var. hondurensis Bar. et Goef. Piracicaba. 1985. $87 \mathrm{f}$. Dissertação (Mestrado em Engenharia Florestal) - Escola Superior de Agricultura "Luiz de Queiroz", Piracicaba, 1985.

\section{EMPRESA BRASILEIRA DE PESQUISA} AGROPECUÁRIA - EMBRAPA. Centro Nacional de Pesquisa de Solos. Sistema brasileiro de classificação de solos. Rio de Janeiro: 1999. 412 p.

GRAHAM, R. D. Genotypic differences in tolerance to manganese deficiency. In: GRAHAM, R. D.; HANNAM, R. J.; UREN, N. C. (Eds.) Manganese in soils and plants. Kluwer Academics Publishers, 1988. p. 261-276.

HAAG, H. P.; DECHEN, A. R.; CARMELLO, Q. A. C. Essências florestais. In: FERREIRA, M. E.; CRUZ, M. C. P. (Eds.) Micronutrientes na agricultura. Piracicaba: POTAFOS/CNPq, 1991a. p. 683-734.

HAAG, H. P.; MARTINEZ, H. E. P.; MORAES, M. L. T. Micronutrientes em Pinus caribaea Morelet II. Níveis internos de cobre e boro sob suficiência e sob omissão. Pesquisa Agropecuária Brasileira, v. 26, n. 3, p. 419-430, $1991 b$.

HAAG, H. P. Nutrição mineral de Eucalyptus, Pinus, Araucaria e Gmelina no Brasil. Campinas: Fundação Cargill, 1983. $101 \mathrm{p}$.

KIMATI, H. et al. (Ed.) Manual de fitopatologia: doenças de plantas cultivadas. 3.ed. São Paulo: CERES. 1997. 774 p.

LASTRA, O. et al. Root uptake and partition of copper, iron, manganese and zinc in Pinus radiata seedlings under different copper supplies. Plant Physiology, v. 132, p. 1622, 1988 .

LA TORRACA, S. M.; HAAG, H. P.; MIGLIORINI, A. J. Recrutamento e exportação de nutrientes por Pinus elliottii var. elliottii em um latossolo vermelho-escuro na região de Agudos, SP. IPEF, v. 27, p. 41-47, 1984.

LILIENFEIN, J. et al. Soil acidification in Pinus caribaea forests on Brazilian savanna Oxisols. Forest Ecology and Management, v. 128, p. 145-157, 2000.

LIMA, R. T. Comportamento de espécies/procedências tropicais do gênero Pinus em Felixlândia-MG - Brasil Região de Cerrados. 1 - Pinus caribaea var. hondurensis e Pinus oocarpa. Revista Árvore, v. 14, n.1, p. 16-25, 1990.

R. Árvore, Viçosa-MG, v.27, n.6, p.769-778, 2003 
LUCAS, R. E.; KNEZEK, D. B. Climatic and soil conditions promoting micronutrient deficiencies in plants. In: MONTVEDT, J. J.; GIORDANO, P. M.; LINDSAY, W. L. (Eds.) Micronutrients in Agriculture. Madison: Soil Science Society of America, 1972. p. 265-288.

MALAVOLTA, E. Elementos de nutrição mineral de plantas. São Paulo: Agronômica Ceres, 1980. 251 p.

MALAVOLTA, E. Nutrição mineral e adubação de plantas cultivadas. São Paulo: Pioneira, 1974. 752 p.

MARTINEZ, H. E. P.et al. Diagnóstico de carência de macronutrientes em três variedades de Pinus caribaea. I. Sintomas visuais e efeitos sobre a produção de matéria seca. Anais da Escola Superior de Agricultura "Luiz de Queiroz”, v. 42, n. 2, p. 539-569, 1985.

MARTINEZ, H. E. P.; HAAG, H. P.; BRUCKNER, C. H. Macronutrientes em Pinus caribaea Morelet. II. Níveis internos sob suficiência e sob omissão. Anais da Escola Superior de Agricultura "Luiz de Queiroz", v. 43, n. 1, p. 97-146, 1986.
MARTINEZ, H. E. P.; HAAG, H. P.; MORAES, M. L. T. Micronutrientes em Pinus caribaea Morelet III. Níveis internos de ferro, manganês e zinco, sob suficiência e sob omissão. Pesquisa Agropecuária Brasileira, v. 27, n. 9, p. 1339-1353, 1992.

MENGEL, K.; KIRKBY, E. A. Principles of plant nutrition. 3.ed. Bern: International Potash Institute, 1982. $655 \mathrm{p}$.

\section{REISSMANN, C. B.; WISNIEWSKI, C. Aspectos}

nutricionais de plantios de Pinus. [on line], Disponível em: $<$ http://agrarias.ufpr.br/ mrlima/pesquisas/R001.htm>. Acesso em: 3 de agosto de 2001.

SAUR, E. Mise au point bibliographique, au sujet de la nutrition oligo-minérale des plantes supérieures. Carences et toxicités chez lês conifères. Annals Science Forest, v. 47, p. 367-389, 1990.

SILVA, F. C. (Org.) Manual de análises químicas de solos, plantas e fertilizantes. Brasília: EMBRAPA, 1999. $370 \mathrm{p}$. 